\title{
Hepatic Coma with Renal Failure, Treated by Repeated Exchange Transfusion
}

\author{
E. N. THOMPSON, J. CAWDERY, and J. MARTIN* \\ From The Hospital for Sick Children, Great Ormond Street, London W.C.1
}

Hepatic coma following acute hepatic necrosis carries a high mortality in spite of conventional therapy (Katz et al., 1962; McDonald and De la Harpe, 1963; Cook and Sherlock, 1965), but the concomitant development of renal failure makes the prognosis even worse (Hecker and Sherlock, 1956). Owing to the extraordinary capacity of the liver to regenerate, other forms of treatment have recently been tried in an endeavour to remove circulating 'toxic' substances, and allow time for regeneration to take place. These methods include exchange transfusion (Lee and Tink, 1958; Trey, Burns, and Saunders, 1966; Berger et al., 1966; Burnell et al., 1967; Jones et al., 1967), heterologous liver perfusion (Eiseman, Liem, and Raffucci, 1965; Eiseman, 1966), and human cross circulation (Burnell et al., 1965). Haemodialysis has not proved to be of any therapeutic benefit though a fall in blood ammonia levels may be achieved (Kiley, Pender, and Welch, 1958; Sherlock, 1961).

Twenty-two cases treated by exchange transfusion have been reported. Considerable variation in the severity may account for the difference in the survival rate in these cases. In the original case and 4 of the 12 described by Trey and his colleagues, a dramatic and curative result followed a single exchange transfusion. However, in 5 other patients where severe renal failure was also present, all succumbed. Coma was alleviated in 14, but only 8 of the 22 patients survived, and in none of these was renal failure present.

We describe the management of a 6-year-old child with progressive coma following multiple exposures to halothane anaesthesia. The cholaemia was complicated by severe renal failure, but recovery eventually occurred.

\section{Case Report}

This 6-year-old child with arthrogryposis multiplex congenita was in excellent health before a Colonna

\footnotetext{
Received December 5, 1967.

* Present address : Alder Hey Children's Hospital, West Derby, Liverpool 12.
}

operation on the left hip. Halothane anaesthesia was used, and $1100 \mathrm{ml}$. blood given. Halothane had been used on 4 separate occasions in the last 6 months, following which an unexplained fever had occurred twice. A blood transfusion also had been given 6 months previously with an earlier operation.

Soon after the last operation she developed a fever which was followed by vomiting, drowsiness, and jaundice. On the third post-operative day she became comatose and was transferred to The Hospital for Sick Children. On admission she was in deep coma and jaundiced with foetor hepaticus; no skin haemorrhages or stigmata of chronic liver disease were noted. The liver dullness was reduced and the spleen impalpable. The urinary output was negligible and routine urinalysis showed no abnormality apart from a trace of protein. The serum bilirubin was $6 \mathrm{mg}$. $/ 100 \mathrm{ml}$, rising within the next 24 hours to $10 \mathrm{mg}$. $/ 100 \mathrm{ml}$; S SGOT and SGPT levels were both greater than $480 \mu$ moles pyruvate/100 $\mathrm{ml}$. per hr., and alkaline phosphatase was $32 \mathrm{King}$ Armstrong units $/ 100 \mathrm{ml}$. Hb $13.8 \mathrm{~g} .100 \mathrm{ml}$., WBC $14,400 / \mathrm{cu} . \mathrm{mm}$., and platelet count $142,000 / \mathrm{cu} . \mathrm{mm}$. The prothrombin time was 62 seconds, partial thromboplastin time was 51.5 seconds, and the serum fibrinogen level was much reduced. The blood urea was $118 \mathrm{mg}$./100 ml., serum Na $131 \mathrm{mEq} / \mathrm{l}$., K. $4 \cdot 7 \mathrm{mEq} / \mathrm{l}$.; there was a metabolic acidosis, with a $p \mathrm{H}$ of $7 \cdot 04$. Arterial blood ammonia level was $113 \mu \mathrm{g} . / 100 \mathrm{ml}$.

The acidosis was corrected with intravenous bicarbonate and the standard regimen for hepatic coma was instituted (Sherlock, 1958). Steroids were not used. Despite these measures, the coma deepened and 12 hours after admission there was no response to painful stimuli, the pupils were widely dilated, and they reacted sluggishly to light. There was an increase in muscle spasm of the limbs and periods of opisthotonos occurred.

Three exchange transfusions were done on the 4 th, 5 th, and 8 th post-operative day. Fresh compatible citrated blood was used, exchanging twice her calculated blood volume on each occasion. Blood was removed from a cannulated radial artery and given via a polyethylene catheter inserted into the superior vena cava via a cut-down on the median antecubital vein. The last exchange transfusion was performed through a single superior vena caval catheter alternately removing and then giving an equal volume of blood.

The renal failure was treated with strict fluid intake, 


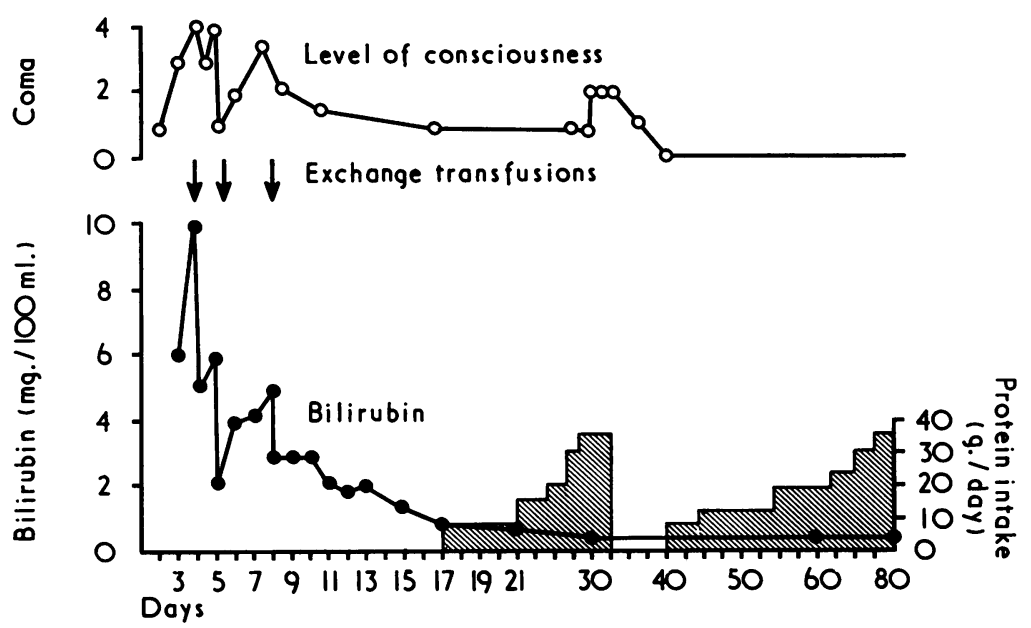

FIG. 1.-Relation between level of consciousness and total serum bilirubin levels, to the exchange transfusions and to the subsequent protein intake.

using $20 \%$ intravenous dextrose. A peritoneal dialysis lasting 24 hours was done on the 8 th day.

A fall in serum bilirubin followed each exchange transfusion (Fig. 1). Despite a slight rebound in bilirubin after the first two exchanges a steady fall occurred after the last transfusion, with normal levels reached at 3 weeks. The serum transaminase levels also slowly returned to normal. In contrast to the metabolic acidosis which had been so severe initially, an alkalosis followed the first exchange and persisted for the next 2 weeks, the $p H$ ranging from $7 \cdot 55-7 \cdot 62$. Initially the arterial ammonia level was $113 \mu \mathrm{g} . / 100 \mathrm{ml}$., falling to $51 \mu \mathrm{g} . / 100 \mathrm{ml}$. after the first exchange transfusion. A low platelet count ranging from $27-60,000 / \mathrm{cu} . \mathrm{mm}$. was noted after the first transfusion and persisted until 8 days after the third, following which the counts were greater than 250,000/cu.mm.

Soon after the last exchange transfusion painful, intermittent, generalized tetanic spasms developed. The serum calcium was $8 \mathrm{mg} . / 100 \mathrm{ml}$. and initially intravenous calcium gluconate was given; only partial symptomatic relief occurred and no change in the serum level obtained. A slight reduction in serum magnesium $(1.5 \mu \mathrm{g} . / 100 \mathrm{ml}$.) was found, but complete control of the tetany was only obtained after the intravenous injection of $2.5 \mathrm{mEq}$ magnesium chloride on two occasions.

Marked oliguria occurred during the first 2 weeks with a mean daily urine output of $130 \mathrm{ml}$. A diuresis occurred 15 days after admission, following which the urine output was normal. On the 8 th day she became oedematous, due to excessive fluid intake. Peritoneal dialysis over a 24-hour period was done and the excess fluid removed, but no effect on her mental status was achieved (Fig. 2).

A further complication on the 10th day was the development of an Esch. coli septicaemia; the organism was found to be most sensitive to colistin sulphomethate.

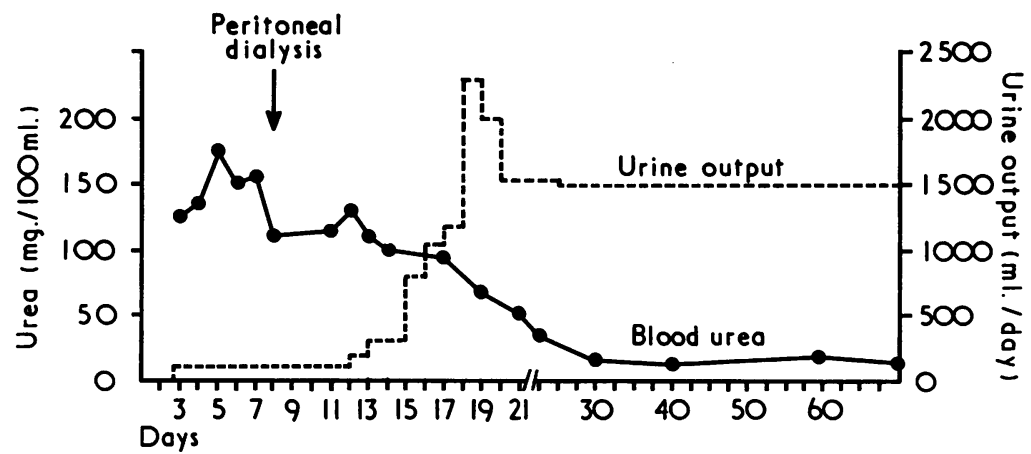

FIG. 2.-Effect of peritoneal dialysis on renal failure, as shown by blood urea and urine output. 
This was administered cautiously because of the associated renal failure, the dose being controlled by serial serum levels.

The level of consciousness was clinically graded into 4: grade 1 alert but mute, grade 2 drowsy but rousable, grade 3 stuporose, and grade 4 deep coma with no response to pain. The level of consciousness improved after each transfusion, the most dramatic effect being after the second. However, consciousness was not maintained until the the third transfusion had been given (Fig. 1). Despite this improvement in level of consciousness she remained mute for 23 days. During this time clinical and serial EEG's failed to show any localized cerebral lesion. Although speechless she seemed to be aware of her surroundings and her comprehension appeared reasonable.

After the introduction of protein into the diet on the 17th day, a gradual increase in muscle spasticity, development of involuntary movements, and intention tremor occurred. The interpretation of these signs was difficult because of the pre-existing arthrogryposis multiplex congenita. The full significance was not appreciated until the onset of a generalized fit with subsequent deterioration in the level of consciousness on the 30th day. This was followed by signs of a left hemiparesis associated with a localized abnormality in the right temporo-parietal region on the EEG. The cause of this was not determined; there was no evidence of a bleeding disorder or systemic infection. In view of this episode and the probability that the preceding signs were due to portal systemic encephalopathy (PSE), protein was withdrawn from the diet and the hepatic failure regimen restarted. Within 3 days she was fully conscious and 10 days later she started to speak, and within a week speech was normal. Rapid regression of the signs of PSE occurred, though the hemiparesis resolved more slowly. Since then progress has been rapid, with return to the pre-operative physical and mental state. Subsequent reintroduction of dietary protein has been well tolerated.

On discharge from hospital 17 weeks after operation, renal and liver function tests were normal. $40 \mathrm{~g}$. protein daily was tolerated well, and no adverse clinical or EEG effects were noted after an ammonium chloride load. The left hemiparesis had resolved though the EEG still showed a localized abnormality. The liver edge was now palpable $2 \mathrm{~cm}$. below the costal margin and felt normal.

\section{Discussion}

In this patient the level of consciousness was improved after each transfusion; however, in spite of this she remained speechless for 6 weeks. The bizarre nature of cerebral involvement in acute and chronic liver disease is known; in some this is transient but in others permanent neurological sequelae occur despite improvement of coma (Read et al., 1967). The prolonged aphasia in our patient is perhaps suggestive of brain damage even though no localized neurological or EEG changes were found at the time. Dietary protein was introduced 10 days after the last transfusion because liver function appeared to be normal. However, the subsequent development of PSE culminating in a fit and left hemiparesis seemed to be related to protein intake, particularly as rapid regression occurred following protein withdrawal. We would, therefore, stress the need to introduce protein very slowly even though liver function appears to be normal.

Citrated fresh blood was used instead of heparinized blood which has been used in the reported cases. No toxic effects were noted apart from a slight reduction in serum calcium and magnesium levels, the latter appearing to be responsible for the tetany, as rapid relief occurred following a small dose of magnesium. Arterial ammonia levels before and after the first transfusion showed a significant fall. No haemorrhagic tendency was noted despite thrombocytopenia. These results suggest that the theoretical risks of citrated blood are of little practical significance, compared to the real hazard of increasing the haemorrhagic tendency by possible inadequate heparin neutralization.

Of all the new methods for treating these patients, exchange transfusion seems the most practical for children, and also a familiar technique for the paediatrician. Although both arterial and venous catheters were used initially, the subsequent use of a single venous catheter proved simpler, as rapid, and only one operator was needed. No difficulties or complications occurred during the procedure.

In patients such as these in whom ultimate hepatic regeneration can be anticipated and where conventional therapy has failed, active methods are justified. This seems particularly pertinent in children. Of the 22 patients reported, 9 were children, 4 of whom survived, compared to only 4 of the 13 adults treated in this way. We feel that our case emphasizes this impression, in view of the additional poor prognostic sign of concomitant renal failure. Although recovery appears complete, we are unable to predict whether cirrhosis will ultimately occur, as the extent of the hepatic architectural damage is not known.

\section{Summary}

A 6-year-old child, with arthrogryposis multiplex congenita, developed acute hepatic necrosis complicated by renal failure after multiple exposures to halothane anaesthesia. The coma was successfully treated by 3 exchange transfusions using fresh citrated blood. Subsequent complications included septicaemia, and a convulsion and left hemiparesis; 17 weeks later renal and hepatic function was 
normal, and cerebral recovery, as judged clinically, was complete.

\section{REPERENCES}

Berger, R. L., Liversage, R. M., Jr., Chalmers, T. C., Graham, J. H., McGoldrick, D. M., and Stohlman, F., Jr. (1966). Exchange transfusion in the treatment of fulminating hepatitis. New Engl. F. Med., 274, 497.

Burnell, J. M., Dawborn, J. K., Epstein, R. B., Gutman, R. A., Leinbach, G. E., Thomas, E. D., and Volwiler, W. (1967). Acute hepatic coma. ibid., 276, 935.

—, Thomas, E. D., Ansell, J. S., Cross, H. E., Dillard, D. H., Epstein, R. B., Eschbach, J. W., Jr., Hogan, R., Hutchings, R. H., Motulsky, A., Ormsby, J. W., Poffenbarger, P., Scribner, B. H., and Volwiler, W. (1965). Observations on cross circulation in man. Amer. F. Med., 38, 832.

Cook, G. C., and Sherlock, S. (1965). Jaundice and its relation to therapeutic agents. Lancet, $1,175$.

Eiseman, B. (1966). Treatment of hepatic coma by extracorporeal liver perfusion. Ann. roy. Coll. Surg. Engl., 38, 329.

—, Liem, D. S., and Raffucci, F. (1965). Heterologous liver perfusion in treatment of hepatic failure. Ann. Surg., 162, 329.

Hecker, R., and Sherlock, S. (1956). Electrolyte and circulatory changes in terminal liver failure. Lancet, $2,1121$.

Jones, E. A., Clain, D., Clink, H. M., MacGillivray, M., and Sherlock, S. (1967). Hepatic coma due to acute hepatic necrosis treated by exchange blood transfusion. ibid., $2,169$.
Katz, R., Velasco, M., Klinger, J., and Alessandri, H. (1962). Corticosteroids in the treatment of acute hepatitis in coma. Gastroenterology, 42, 258.

Kiley, J. E., Pender, J. C., and Welch, H. F. (1958). Ammonia intoxication treated by hemodialysis. New Engl. F. Med., 259, 1156.

Lee, C., and Tink, A. (1958). Exchange transfusion in hepatic coma. Med. F. Aust., 1, 40.

McDonald, R., and De la Harpe, P. L. (1963). Hepatic coma in childhood. F. Pediat., 63, 916.

Read, A. E., Sherlock, S., Laidlaw, J., and Walker, J. G. (1967). The neuro-psychiatric syndromes associated with chronic liver disease and an extensive portal-systemic collateral circulation. Quart. F. Med., 36, 135.

Sherlock, S. (1958). Pathogenesis and management of hepatic coma. Amer. J. Med., 24, 805.

- (1961). Hepatic coma. Gastroenterology, 41, 1.

Trey, C., Burns, D. G., and Saunders, S. J. (1966). Treatment of hepatic coma by exchange blood transfusion. New Engl. $\mathcal{f}$. Med., 274, 473.

Zacarías, J. S., Brinck, P., and Huidobro, J. G. (1967). Exchange transfusion in the treatment of hepatic coma. f. Pediat., 71, 660.

\section{Addendum}

Since this paper was completed 3 further children treated in this way have been reported by Zacarias, Brinck, and Huidobro (1967). All survived, emphasizing the value of this form of therapy in childhood. 